\title{
Talairach Space
}

National Cancer Institute

\section{Source}

National Cancer Institute. Talairach Space. NCI Thesaurus. Code C94990.

A widely accepted standard coordinate system of brain physiologically-based regions, i.e. an atlas space, to which an individual brain geometry from a scan can be transformed and realigned for purposes of matching corresponding regions among brains. 